\title{
Effects of dexmedetomidine on postoperative cognitive function in patients undergoing coronary artery bypass grafting
}

\author{
ZHENG GONG ${ }^{*}$, JUN LI* ${ }^{*}$ YULING ZHONG, XUEHAI GUAN, AILAN HUANG and LI MA \\ Department of Anesthesiology, The People's Hospital of Guangxi Zhuang Autonomous Region, \\ Nanning, Guangxi 530021, P.R. China
}

Received November 27, 2017; Accepted September 4, 2018

DOI: $10.3892 / \mathrm{etm} .2018 .6778$

\begin{abstract}
Effects of dexmedetomidine on postoperative cognitive function in patients undergoing coronary artery bypass grafting were investigated. Eighty patients undergoing systemic anesthesia with extracorporeal coronary artery bypass grafting in The People's Hospital of Guangxi Zhuang Autonomous Region from January 2015 to August 2017 were selected and randomly divided into the observation group $(n=40)$ and control group $(n=40)$. The two groups were treated with dexmedetomidine and equal volume of normal saline, respectively. Moreover, safety indexes including EEG bispectral index (BIS) at $30 \mathrm{~min}$ before induction of anesthesia (T0), immediately after intubation (T1), when incision was made (T2), when chest was closed (T3), when operation was completed (T4) and at $6 \mathrm{~h}$ after operation (T5), intraoperative circulatory system-related complications, cortisol, epinephrine and norepinephrine levels at the end of surgery as well as anesthesia recovery time and postoperative mechanical ventilation time were recorded and compared. All the patients were followed up for 1 week. Mini-mental state examination (MMSE) and Montreal cognitive assessment (MoCA) were administered at 1, 3 and 7 days after operation, and the incidence of intraoperative awareness and postoperative cognitive dysfunction was recorded. BIS value in the observation group was lower than that in the control group $(\mathrm{P}<0.05)$ at T1-T4 time points, and the BIS value in the observation group was higher than that in the control group $(\mathrm{P}<0.05)$ at T5. Incidence rates of intraoperative arrhythmia, hypertension and hypotension in the observation group was significantly lower than those in the control group $(\mathrm{P}<0.05)$. At the end of operation, levels of cortisol, epinephrine and norepinephrine
\end{abstract}

Correspondence to: Dr Li Ma, Department of Anesthesiology, The People's Hospital of Guangxi Zhuang Autonomous Region, 6 Taoyuan Road, Nanning, Guangxi 530021, P.R. China

E-mail: im56ap@163.com

*Contributed equally

Key words: dexmedetomidine, cardiopulmonary bypass, coronary artery bypass, postoperative cognitive function in the observation group were significantly lower than those in the control group $(\mathrm{P}<0.05)$. Anesthesia recovery time and postoperative mechanical ventilation time in the observation group was significantly shorter than the time in the control group $(\mathrm{P}<0.05)$. MMSE and MoCA scores of the observation group were better than those of the control group $(\mathrm{P}<0.05)$. The incidence of cognitive impairment and postoperative cognitive impairment in the observation group was significantly lower than those in the control group $(\mathrm{P}<0.05)$. Therefore, it is concluded that dexmedetomidine can effectively reduce the incidence of postoperative cognitive impairment in patients undergoing coronary artery bypass grafting, and it is of high safety for circulatory function.

\section{Introduction}

Postoperative cognitive dysfunction is defined as postoperative consciousness, cognitive function, memory and orientation disorders, complicated with mental and sleep disorders in patients without mental illness before operation. Postoperative cognitive dysfunction is caused by postoperative neurological disorders due to various factors including brain disorders (1). Strong surgical stimulation caused by cardiac surgery may lead to significant body stress response, leading to increased level of catecholamines secreted by sympathetic nervous system (2). In particular, bypass coronary artery bypass grafting is considered to be one of the most common predisposing factors for postoperative cognitive impairment during cardiopulmonary bypass (3).

In recent years, with the development of anesthesia and cardiopulmonary bypass technology, incidence of postoperative cognitive dysfunction was significantly decreased, but still cannot be eradicated (4). Dexmedetomidine, as a new and efficient adrenergic receptor agonist $\alpha 2$, can induce physiological sleep (5). Dexmedetomidine can also effectively inhibit the body's inflammatory response and thus improve the protection of the nervous system (6). This study mainly explores the impact of dexmedetomidine on postoperative cognitive function in patients with coronary artery bypass grafting.

\section{Patients and methods}

General information. A total of 80 patients undergoing systemic anesthesia and extracorporeal coronary artery 
Table I. Comparison of general information between the two groups.

\begin{tabular}{lcccccccc}
\hline & $\begin{array}{c}\text { Sex } \\
(\text { male/ } \\
\text { female) }\end{array}$ & $\begin{array}{c}\text { Age } \\
\text { (years) }\end{array}$ & $\begin{array}{c}\text { Body } \\
\text { mass } \\
\text { index } \\
\left(\mathrm{kg} / \mathrm{m}^{2}\right)\end{array}$ & $\begin{array}{c}\text { Left } \\
\text { ventricular } \\
\text { ejection } \\
\text { fraction }(\%)\end{array}$ & $\begin{array}{c}\text { Intraoperative } \\
\text { cardiopulmonary } \\
\text { bypass time } \\
(\text { min) }\end{array}$ & $\begin{array}{c}\text { Total } \\
\text { operation } \\
\text { time (min) }\end{array}$ & MMSE & MoCA \\
\hline Observation $(\mathrm{n}=40)$ & $28 / 12$ & $42.3 \pm 1.6$ & $23.5 \pm 1.1$ & $53.1 \pm 2.1$ & $113.0 \pm 5.1$ & $206.5 \pm 15.3$ & $28.5 \pm 0.2$ & $28.1 \pm 0.5$ \\
Control $(\mathrm{n}=40)$ & $27 / 13$ & $42.4 \pm 1.5$ & $23.6 \pm 1.0$ & $53.0 \pm 2.0$ & $113.1 \pm 5.0$ & $206.4 \pm 15.2$ & $28.6 \pm 0.3$ & $28.2 \pm 0.6$ \\
t or $\chi^{2}$ value & 0.001 & 0.288 & 0.425 & 0.218 & 0.089 & 0.029 & 1.754 & 0.810 \\
p-value & 0.999 & 0.774 & 0.672 & 0.828 & 0.930 & 0.977 & 0.083 & 0.421 \\
\hline
\end{tabular}

bypass surgery in the People's Hospital of Guangxi Zhuang Autonomous Region (Nanning, China) from January 2015 to August 2017 were selected. Patients were diagnosed by preoperative imaging, clinical manifestations, and direct observations during surgery. Patients with cognitive impairment, mental and psychological illness and chronic alcoholics, drug addicts, abuse of psychotropic substances, illiterate education, intraoperative use of epinephrine and norepinephrine, or allergy to drugs used in this study were excluded. This study was approved by the Ethics Committee of the People's Hospital of Guangxi Zhuang Autonomous Region, and all patients signed informed consent. Patients were randomly divided into two groups, 40 cases in each group. No significant differences in sex, average age, body mass index (BMI), left ventricular ejection fraction, intraoperative cardiopulmonary bypass time and total operation time were found between the groups $(\mathrm{P}>0.05)$. Preoperative mini-mental state examination (MMSE) and Montreal Cognitive Assessment (MoCA, Beijing version) were performed and no significant differences in MMSE and MoCA scores were found between the groups (Table I).

Method. All patients underwent surgical treatment under general anesthesia with endotracheal intubation. Patients were fasted and not allowed to drink water before operation. Peripheral vein was opened and connected to the monitor, and patient's noninvasive blood pressure, electrocardiogram, heart rate and oxygen saturation were monitored continuously. Anesthesia machine was used to detect the changes of respiratory function in patients. Anesthesia was induced by intravenous infusion of midazolam, fentanyl, cisatracurium and etomidate. Tracheal intubation was performed under slow induction of anesthesia, and was connected to anesthesia machine for mechanical ventilation, oxygen flow rate was set to $50 \%$, respiratory rate was set to 14 times/min, and tidal volume was set according to patient weight $(10 \mathrm{ml} / \mathrm{kg})$. Peripheral arterial puncture, central venous catheterization and pressure measurement were performed. Intraoperative anesthesia was performed by using propofol, remifentanil and cisatracurium. Cardiopulmonary bypass technology was used. Dexmedetomidine (SFDA approval number: H20130027, CISEN), solution $(4 \mu \mathrm{g} / \mathrm{ml})$ was prepared and pumped into patients in the observation group through a vein with a dose of $1 \mu \mathrm{g} / \mathrm{kg}$ during the first $10 \mathrm{~min}$, followed by the dose of $0.2 \mu \mathrm{g} / \mathrm{kg}$ until the end of surgery. Equal volume of $0.9 \%$ saline was used at the same speed for patients in the control group, and $1 \mathrm{mg}$ of midazolam was intravenously administered every $30 \mathrm{~min}$. Based on patient circulatory function, vasoactive drug was given through extracorporeal circulation machine during surgery, and vasoactive drugs were intravenously administered after cardiopulmonary bypass. All patients had the same indications for the use of vasoactive drugs, and drugs used here included: popamine, metaxylamine, epinephrine, phenylephrine and norepinephrine.

Observation indexes. Circulatory function-related complications, such as arrhythmia, hypertension, and hypotension were compared between the two groups. BIS was recorded at $30 \mathrm{~min}$ before induction of anesthesia (T0), immediately after intubation (T1), when incision was made (T2), when chest was closed (T3), when operation was completed (T4) and at $6 \mathrm{~h}$ after operation (T5). The levels of cortisol, epinephrine and norepinephrine at the end of operation were recorded, and recovery time and mechanical ventilation time of the two groups were compared. MMSE and MoCA were performed at 1,3 and 7 days after operation. The incidence rates of intraoperative awareness and postoperative cognitive dysfunction in the two groups were compared.

Assessment criteria. BIS value was measured by using A-3000 BIS monitor (Aspect Medical System, Covidien, MA, USA) and its ancillary equipment. BIS value fluctuated between 1 and 100. The higher the BIS value is, the higher the sober level is. BIS higher than $95 \%$ indicated completely awaken state, and BIS lower than $70 \%$ indicated disorder of consciousness. Stress factors, including cortisol ( $80-550 \mathrm{nmol} / \mathrm{l})$, epinephrine $(<480 \mathrm{pmol} / \mathrm{l})$ and norepinephrine (615-3240 pmol/l), were measured by Bio-Rad 450 automatic biochemical analyzer (Bio-Rad Laboratories, Inc., Hercules, CA, USA). MMSE contains seven aspects and 30 questions with a score of 0 to 30 , and 27 points was the threshold for cognitive impairment. Lower MMSE score indicated more severe cognitive impairment. MoCA: Test was completed within $10 \mathrm{~min}$, and the highest score was 30 points, and the lowest score was 0 . A score over 26 points indicated normal conditions. Lower MoCA score indicated more severe cognitive impairment. MoCA was not performed within $60 \mathrm{~min}$ after MMSE, and MMSE was not performed within $24 \mathrm{~h}$ after MoCA. Arrhythmias are indicated by electrocardiogram. Hypertension in anesthesia means: blood pressure is greater than $140 / 95 \mathrm{mmHg}$ or elevated blood pressure is greater than $20 \%$. Hypotension in anesthesia was defined as: blood pressure is less than $90 / 60 \mathrm{mmHg}$ or decreased blood pressure is greater than $30 \%$. 


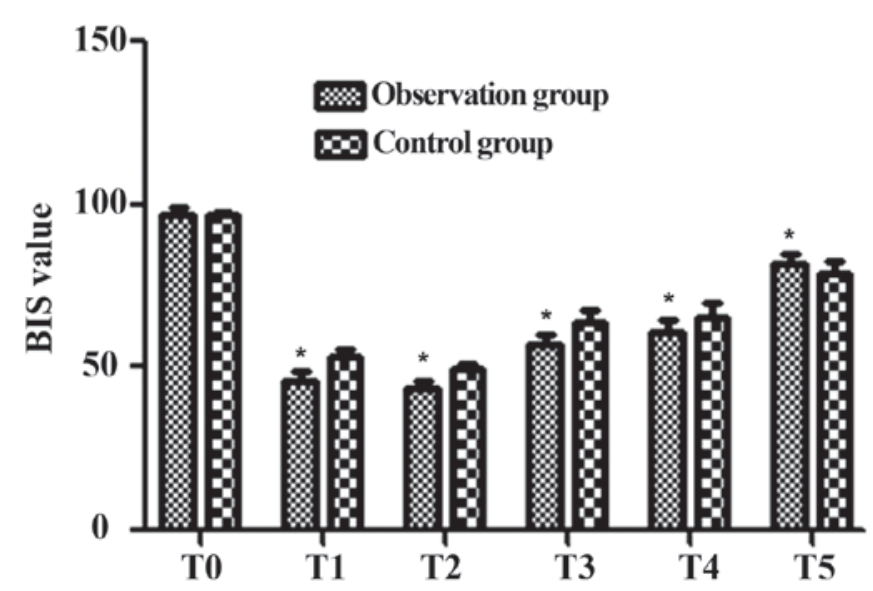

Figure 1. Comparison of BIS values between the two groups at different time-points. BIS values in the observation group were lower than those in the control group at T1 to T4, while BIS value in the observation group was higher than that in the control group at T5. ${ }^{*} \mathrm{P}<0.05$ compared with the control group.

Table II. Comparison of intraoperative circulatory functionrelated complications between the two groups.

Total

Groups Arrhythmia Hypertension Hypotension incidence

\begin{tabular}{lcccc}
\hline $\begin{array}{l}\text { Observation } \\
(\mathrm{n}=40)\end{array}$ & 1 & 1 & 1 & $3(7.5 \%)$ \\
$\begin{array}{l}\text { Control } \\
(\mathrm{n}=40)\end{array}$ & 3 & 4 & 4 & $11(27.5 \%)$ \\
$\chi^{2}$ value & & - & & 4.242 \\
P-value & & - & & 0.039 \\
\hline
\end{tabular}

Statistical analysis. SPSS13.0 (SPSS, Inc., Chicago, IL, USA) was used. Measurement data are expressed as mean \pm standard deviation. Comparisons of mean values between the two groups were performed by using t-test, and intragroup comparisons were performed by $\chi^{2}$ test. $\mathrm{P}<0.05$ was considered to indicate a statistically significant difference.

\section{Results}

Comparison of BIS values between the two groups at different time-points. BIS values in the observation group at T0-T5 were $96.8 \pm 2.0,45.8 \pm 2.9,43.3 \pm 2.3,56.9 \pm 3.1,60.9 \pm 3.5$ and $81.9 \pm 3.3$, respectively, and BIS values in the control group at T0-T5 were $96.9 \pm 1.0,53.3 \pm 2.6,49.6 \pm 1.8,63.5 \pm 3.9,65.3 \pm 4.6$ and 78.9 \pm 3.6 , respectively. BIS values in the observation group were significantly lower than those in the control group at $\mathrm{T} 1$ to $\mathrm{T} 4(\mathrm{t}=8.931,4.980,8.379$ and $4.814, \mathrm{P}<0.05)$, while BIS value in the observation group was significantly higher than that in the control group at T5 ( $\mathrm{t}=3.885, \mathrm{P}<0.05)$ (Fig. 1).

Comparison of intraoperative circulatory function-related complications between the two groups. The incidence rates of intraoperative arrhythmia, hypertension and hypotension in the observation group were significantly lower than those in the control group $(\mathrm{P}<0.05)$ (Table II).
Table III. Comparison of levels of cortisol, epinephrine and norepinephrine at the end of operation between the two groups $($ mean \pm SD) .

\begin{tabular}{lccc}
\hline Groups & $\begin{array}{c}\text { Cortisol } \\
(\mathrm{nmol} / \mathrm{l})\end{array}$ & $\begin{array}{c}\text { Epinephrine } \\
(\mathrm{pmol} / \mathrm{l})\end{array}$ & $\begin{array}{c}\text { Norepinephrine } \\
(\mathrm{pmol} / \mathrm{l})\end{array}$ \\
\hline Observation $(\mathrm{n}=40)$ & $10.1 \pm 0.7$ & $50.3 \pm 2.3$ & $58.5 \pm 5.0$ \\
Control $(\mathrm{n}=40)$ & $23.2 \pm 1.9$ & $100.1 \pm 6.5$ & $179.6 \pm 11.7$ \\
t value & 40.918 & 45.680 & 60.196 \\
P-value & $<0.001$ & $<0.001$ & $<0.001$ \\
\hline
\end{tabular}

Table IV. Comparison of anesthesia recovery time and mechanical ventilation time between the two groups $(h$, mean $\pm S D)$.

\begin{tabular}{lcc}
\hline Groups & $\begin{array}{c}\text { Anesthesia } \\
\text { recovery } \\
\text { time }\end{array}$ & $\begin{array}{c}\text { Mechanical } \\
\text { ventilation } \\
\text { time }\end{array}$ \\
\hline Observation $(\mathrm{n}=40)$ & $6.2 \pm 0.8$ & $13.8 \pm 2.1$ \\
Control $(\mathrm{n}=40)$ & $9.9 \pm 1.3$ & $18.6 \pm 2.6$ \\
t value & 15.330 & 9.083 \\
P-value & $<0.001$ & $<0.001$ \\
\hline
\end{tabular}

Comparison of levels of cortisol, epinephrine and norepinephrine between the two groups at the end of operation. At the end of surgery, the levels of cortisol, epinephrine and norepinephrine in the observation group were significantly lower than those in the control group $(\mathrm{P}<0.05)$ (Table III).

Comparison of anesthesia recovery time and mechanical ventilation time between the two groups. Anesthesia recovery time in the observation group was significantly shorter than that in the control group $(\mathrm{P}<0.05)$, and postoperative mechanical ventilation time in the observation group was also significantly shorter than that in the control group $(\mathrm{P}<0.05)$ (Table IV).

Changes in MMSE during follow-up. MMSE scores in the observation group were $20.6 \pm 0.5$ points, $25.1 \pm 0.7$ points and $28.6 \pm 0.3$ points at 1 day, 3 days and 7 days after operation, respectively. MMSE scores in the control group were $17.5 \pm 0.9$ points, $21.3 \pm 1.1$ points and $23.8 \pm 0.7$ points at 1 day, 3 days and 7 days after operation, respectively. MMSE scores in the observation group were significantly higher than those in the control group at the three time points $(\mathrm{t}=19.043,18.433$ and 39.862, $\mathrm{P}<0.001$ ) (Fig. 2).

Changes in MoCA during follow-up. MoCA scores were $18.6 \pm 1.5$ points, $25.6 \pm 1.0$ points and $27.4 \pm 0.6$ points in the observation group at 1 day, 3 days and 7 days after operation, respectively, and MoCA scores in the control group were $16.3 \pm 1.3$ points, $21.5 \pm 0.8$ points and $24.3 \pm 0.8$ points at 1 day, 3 days and 7 days after operation, respectively. MoCA scores in the observation group were significantly higher than those in the control group $(\mathrm{t}=7.328,20.248$ and 19.606, $\mathrm{P}<0.001<0.05$ ) (Fig. 3). 


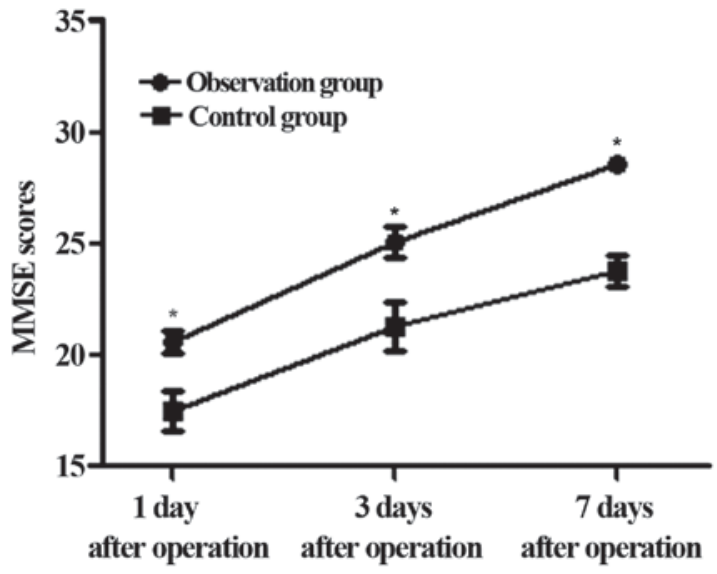

Figure 2. Changes in MMSE during follow-up. MMSE scores in the observation group were significantly higher than those in the control group at 1 day, 3 days and 7 days after operation $(\mathrm{P}<0.05)$. ${ }^{*} \mathrm{P}<0.05$ compared with the control group.

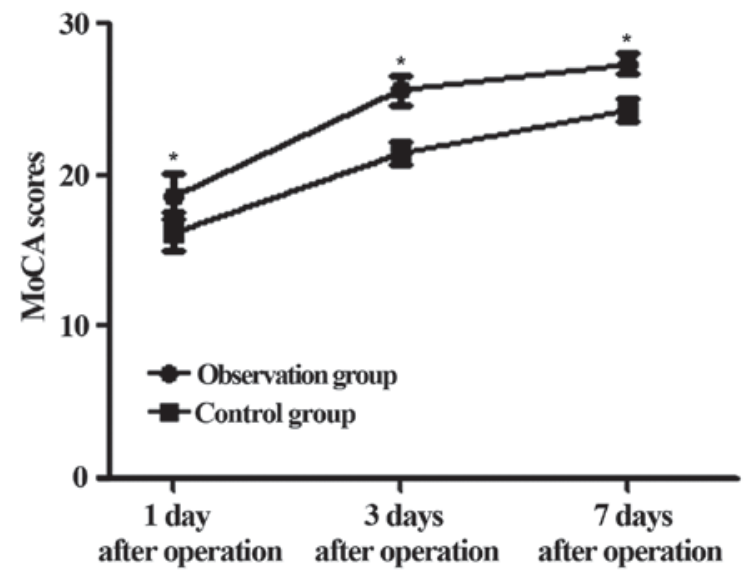

Figure 3. Changes in MoCA during follow-up. MoCA scores in the observation group were significantly higher than those in the control group at 1 day, 3 days and 7 days after operation. ${ }^{*} \mathrm{P}<0.05$ compared with the control group.

Comparison of intraoperative awareness and postoperative cognitive impairment between the two groups. The incidence rates of intraoperative awareness and postoperative cognitive impairment in the observation group were significantly lower than those in the control group (Table V).

\section{Discussion}

Postoperative cognitive impairment is a relatively mild clinical cognitive disorder, but it may cause decreased social activities for a few weeks or months, leading to decreased self-care ability (7). Incidence of postoperative cognitive impairment in patients with coronary artery surgery was significantly higher than that in patients without the surgery (8). Studies have shown that $>40 \%$ patients will develop cognitive dysfunction within 7 days after coronary artery-related surgery (9), and the incidence in elderly patients is even higher. Dexmedetomidine is currently the most widely used $\alpha 2$ adrenergic receptor agonist in the clinical treatment (10). Dexmedetomidine can induce physiological sleep, achieve certain synergistic analgesic and sympathetic inhibitory effects (11). Previous studies (12)
Table V. Comparison of intraoperative awareness and postoperative cognitive impairment between the two groups (cases, $\%)$.

\begin{tabular}{lcc}
\hline Groups & $\begin{array}{c}\text { Intraoperative } \\
\text { awareness }\end{array}$ & $\begin{array}{c}\text { Postoperative cognitive } \\
\text { impairment }\end{array}$ \\
\hline Observation $(\mathrm{n}=40)$ & $1(2.5)$ & $1(2.5)$ \\
Control $(\mathrm{n}=40)$ & $9(22.5)$ & $10(25)$ \\
$\chi^{2}$ value & 5.600 & 6.746 \\
P-value & 0.018 & 0.009 \\
\hline
\end{tabular}

have shown that dexmedetomidine can reduce body stress, inflammation, and inhibit oxidation reaction. Application of dexmedetomidine in anesthesia can maintain sedation, accelerate recovery and reduce the feeling of being drunk (13).

The patients in the observation group were treated with dexmedetomidine. It was found that BIS values in the observation group were lower than those in the control group at T1 to T4 (T1: immediately after intubation, T2: when incision was made, T3: when chest was closed, T4: when operation was completed), while BIS value in the observation group was higher than that in the control group at T5 (6 h after operation, $\mathrm{t}=3.885, \mathrm{P}<0.05)$. The sedative effect was significantly better in the observation group than in the control group, suggesting that intraoperative sedation effect of dexmedetomidine can accelerate postoperative recovery. Comparison of cyclic function related complications showed that the incidence rates of arrhythmia, hypertension and hypotension were significantly lower in the observation group than in the control group, indicating that dexmedetomidine is safer than midazolam for circulatory function. The comparison of levels of cortisol, epinephrine and norepinephrine at the end of surgery showed that the levels of cortisol, epinephrine and norepinephrine in the observation group were significantly lower than those in the control group, indicating that dexmedetomidine can effectively inhibit the body's stress response and reduce catecholamine hormone secretion. The comparison of anesthesia recovery time and mechanical ventilation time showed that anesthesia recovery time and mechanical ventilation time were significantly shorter in the observation group than in the control group, indicating that dexmedetomidine can effectively shorten the postoperative mechanical ventilation, and promote postoperative recovery. The comparison of MMSE and MoCA scores showed that MMSE and MoCA scores in the observation group were significantly higher than those in the control group at 1 day, 3 days and 7 days after operation, and the incidence rates of intraoperative awareness and postoperative cognitive dysfunction were significantly lower in the observation group than in the control group, indicating that dexmedetomidine can effectively improve postoperative cognitive function and reduce the incidence of intraoperative awareness.

Continuous intravenous infusion of dexmedetomidine can alleviate the severity of the patient's stress response and reduce catecholamine hormone secretion (14), thereby reducing the activity of the sympathetic nervous system, effectively stabilizing patient's hemodynamics (15), alleviating the stress reaction, reducing the trauma to the body caused by operation 
and anesthesia stimulation and ischemia-reperfusion injury caused by extracorporeal circulation, and improving the protection effects on the nervous system (16). Dexmedetomidine can also inhibit monocyte Toll-like receptor-1 and Toll-like receptor-2 expression (17), thereby reducing the body's inflammatory response (18) and reducing the incidence of postoperative cognitive dysfunction. In addition, the use of dexmedetomidine can reduce glutamate neurotoxicity (19) and apoptosis of neuronal cells (20). Therefore, it is of great significance to relieve postoperative cognitive dysfunction in patients.

In conclusion, dexmedetomidine can effectively reduce the incidence of postoperative cognitive dysfunction in patients undergoing cardiopulmonary bypass surgery and it is of high safety for circulatory function.

\section{Acknowledgements}

Not applicable.

\section{Funding}

This study was supported by the Self-financing research project of the Health and Family Planning Commission of Guangxi Zhuang Autonomous Region (nos. Z20180699, Z20170363 and Z2012259).

\section{Availability of data and materials}

The datasets used and/or analyzed during the present study are available from the corresponding author on reasonable request.

\section{Authors' contributions}

ZG and LM conceived and designed the study. ZG, JL and YZ were responsible for the collection and analysis of the patient data. JL, XG and $\mathrm{AH}$ interpreted the data and drafted the manuscript. JL and LM revised the manuscript critically for important intellectual content. All authors read and approved the final manuscript.

\section{Ethics approval and consent to participate}

The study was approved by the Ethics Committee of the People's Hospital of Guangxi Zhuang Autonomous Region (Nanning, China). Signed informed consents were obtained from the patients or the guardians.

\section{Patient consent for publication}

Not applicable.

\section{Competing interests}

The authors declare that they have no competing interests.

\section{References}

1. Jo YY, Kim JY, Lee JY, Choi CH, Chang YJ and Kwak HJ The effect of intraoperative dexmedetomidine on acute kidney injury after pediatric congenital heart surgery: A prospective randomized trial. Medicine (Baltimore) 96: e7480, 2017.
2. Anton-Martin P, Modem V, Taylor D, Potter D and Darnell-Bowens C: A retrospective study of sedation and analgesic requirements of pediatric patients on extracorporeal membrane oxygenation (ECMO) from a single-center experience. Perfusion 32: 183-191, 2017.

3. Bulow NMH, Colpo E, Pereira RP, Correa EFM, Waczuk EP, Duarte MF and Rocha JBT: Dexmedetomidine decreases the inflammatory response to myocardial surgery under minicardiopulmonary bypass. Braz J Med Biol Res 49: e4646, 2016.

4. Cheng X, Zuo Y, Zhao Q, Gu E and Huang Y: Comparison of the effects of dexmedetomidine and propofol on hemodynamics and oxygen balance in children with complex congenital heart disease undergoing cardiac surgery. Congenit Heart Dis 10: E123-E130, 2015.

5. KlamtJG, Vicente WV, Garcia LV andFerreiraCA:Hemodynamic effects of the combination of dexmedetomidine-fentanyl versus midazolam-fentanyl in children undergoing cardiac surgery with cardiopulmonary bypass. Rev Bras Anestesiol 60: 350-362, 2010.

6. Tang W, Wang J, Fu GQ and Yuan L: Effect of dexmedetomidine and midazolam on respiration and circulation functions in patients undergoing open heart surgery under acupunctureassisted general anesthesia. Zhen Ci Yan Jiu 39: 216-221, 2014 (In Chinese).

7. Ueki M, Kawasaki T, Habe K, Hamada K, Kawasaki C and Sata T: The effects of dexmedetomidine on inflammatory mediators after cardiopulmonary bypass. Anaesthesia 69: 693-700, 2014.

8. Ji F, Li Z, Young JN, Yeranossian A and Liu H: Post-bypass dexmedetomidine use and postoperative acute kidney injury in patients undergoing cardiac surgery with cardiopulmonary bypass. PLoS One 8: e77446, 2013

9. Lu JG, Pensiero A, Aponte-Patel L, Velez de Villa B, Rusanov A, Cheng B, Cabreriza SE and Spotnitz HM: Short-term reduction in intrinsic heart rate during biventricular pacing after cardiac surgery: A substudy of a randomized clinical trial. J Thorac Cardiovasc Surg 146: 1494-1500, 2013.

10. Curtis JA, Hollinger MK and Jain HB: Propofol-based versus dexmedetomidine-based sedation in cardiac surgery patients. J Cardiothorac Vasc Anesth 27: 1289-1294, 2013.

11. Bhaskar P, John J, Sivamurthy SK, Lone RA, Tysarowski PA, Riyas MK, Syed SA, Bhat AN and Sallehuddin A: Anesthetic management of an infant with Joubert syndrome for cardiac surgery. J Clin Anesth 25: 488-490, 2013.

12. Naguib AN, Tobias JD, Hall MW, Cismowski MJ, Miao Y, Barry N, Preston T, Galantowicz M and Hoffman TM: The role of different anesthetic techniques in altering the stress response during cardiac surgery in children: A prospective, doubleblinded, and randomized study. Pediatr Crit Care Med 14: 481-490, 2013

13. Wagner D, Pasko D, Phillips K, Waldvogel J and Annich G: In vitro clearance of dexmedetomidine in extracorporeal membrane oxygenation. Perfusion 28: 40-46, 2013.

14. Neema PK: Dexmedetomidine in pediatric cardiac anesthesia. Ann Card Anaesth 15: 177-179, 2012.

15. Yoshitomi O, Cho S, Hara T, Shibata I, Maekawa T, Ureshino H and Sumikawa K: Direct protective effects of dexmedetomidine against myocardial ischemia-reperfusion injury in anesthetized pigs. Shock 38: 92-97, 2012.

16. Kunisawa T, Ueno M, Kurosawa A, Nagashima M, Hayashi D, Sasakawa T, Suzuki A, Takahata O and Iwasaki H: Dexmedetomidine can stabilize hemodynamics and spare anesthetics before cardiopulmonary bypass. J Anesth 25: 818-822, 2011.

17. Huang J, Dinh M, Kuchle N and Zhou J: Anesthetic management for combined mitral valve replacement and aortic valve repair in a patient with osteogenesis imperfecta. Ann Card Anaesth 14: $115-118,2011$.

18. Leino K, Hynynen M, Jalonen J, Salmenperä M, Scheinin H and Aantaa R; Dexmedetomidine in Cardiac Surgery Study Group: Renal effects of dexmedetomidine during coronary artery bypass surgery: A randomized placebo-controlled study. BMC Anesthesiol 11: 9, 2011.

19. Butt WW: Minimize stress and maximize clinical outcome! Pediatr Crit Care Med 14: 547-548, 2013.

20. Maldonado JR, Wysong A, van der Starre PJ, Block T, Miller C and Reitz BA: Dexmedetomidine and the reduction of postoperative delirium after cardiac surgery. Psychosomatics 50: 206-217, 2009.

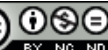

This work is licensed under a Creative Commons Attribution-NonCommercial-NoDerivatives 4.0 International (CC BY-NC-ND 4.0) License. 